\title{
A Study about Brahmi (Bacopa monnieri) Preparation Steps on Its Saponin Quantity
}

\author{
Bunyaporn Nichakool ${ }^{1}$, Amporn Jamphon', Yupa Pootang-on ${ }^{2}$, \\ Weerawan Techakriengkrai ${ }^{3}$ and Taweesak Techakriengkrai ${ }^{1, *}$ \\ ${ }^{I}$ Department of Home Economic, Faculty of Agriculture, Kasetsart University, Bangkok 10900, Thailand \\ ${ }^{2}$ Faculty of Animal Sciences and Agricultural Technology, Silpakorn University, Phetchaburi IT Campus, \\ Cha-am, Phetchaburi 76120, Thailand \\ ${ }^{3}$ Nutrition Therapeutic Department, Bangkok Hospital, Bangkok 10310, Thailand
}

('Corresponding author's e-mail: fagrtst@ku.ac.th)

Received: 22 February 2021, Revised: 23 June 2021, Accepted: 24 July 2021

\begin{abstract}
Brahmi (Bacopa monnieri) is a medicinal herb containing bioactive compounds (Bacosides) in the saponin group that enhances memory and prevents dementia. Brahmi is not favored for cooking because it is very bitter. Nowadays, most people consume Brahmi as supplementary food, which makes it more expensive than consuming in food form, not getting fibers and other nutrients. Currently, there are only few studies that work to alleviate in Brahmi. Therefore, this study aimed to find out the saponin quantity in Brahmi after some pretreatments and the effect of these treatments on Bacosides and bitterness. Thus, suitable preparation steps for Brahmi have the highest remaining saponin quantity and are consumable. There were various techniques of preparation, depending on the concentration of salt used in crumpling and 1 time boiling of Brahmi to reduce its bitterness. The salt concentrations used in this study were 0 , 10 , and $20 \%(\mathrm{w} / \mathrm{w})$ compared with the fresh herb. The saponin quantity was analyzed by highperformance liquid chromatography (HPLC). The results showed that the total amount of saponin in boiled Brahmi that crumpled with 0,10 , and $20 \%$ were significantly lower than fresh Brahmi $(p<0.05)$. Brahmi was crumpled with $10 \%$ salt before boiling had the highest total saponin quantity of $2.69 \pm 0.02$ $\mathrm{g} / \mathrm{kg}$ of fresh weight and the highest tasting scores. Thus, the preparation of crumpling with $10 \%$ salt before cooking, was suitable because consumers gained the highest saponin and accepted the taste of food containing Brahmi.
\end{abstract}

Keywords: Brahmi, Saponin, Boiling, Salt, Bitterness

\section{Introduction}

Brahmi (Bacopa monnieri) is a medicinal plant in Nepal and India but can found in Thailand. In the past, Sardsaengjun [1] mentioned that Thai traditional medicine used Brahmi as a brain tonic and epilepsy drug. According to Le et al. [2], Brahmi has the bioactive compounds for memory enhancing included in saponin glycosides such as Bacoside $\mathrm{A}_{3}$, Bacopasaponin $\mathrm{C}$, Bacopaside I, Bacopaside II, and Bacopaside $\mathrm{X}$ (Bacopasaponin $\mathrm{C}$ isomer). Pravina et al. [3] also found that the bioactive compounds in Brahmi were safe, used to revive the memory when study in 23 healthy volunteers who orally taken 1 single capsule of Brahmi extract daily for 30 days. Mild adverse effects related to the gastrointestinal system observed in the trial, which subsided spontaneously. Rungrojvuthikul's study [4] reported that memory score in the subjects who take $300 \mathrm{mg}$ of Brahmi extract daily for 2 months greater than the placebo group. Moreover, Kumar et al. [5] found taking Bacognize (with $150 \mathrm{mg}$ Brahmi extract per tablet) for 6 weeks had better memory and language comprehension than a placebo. Nowadays, most people know that Brahmi as supplementary food can improve memory and prevent dementia.

In a preliminary investigation, the results showed that there was a limitation of using Brahmi for cooking in which the freshly, blanched, or boiled. Brahmi had more bitter taste than Bitter gourd, Khi lek leaves, and Neem leaves. Therefore, the bitterness of Brahmi should be reduced before cooking. Savage [6] and Price et al. [7] noted bitterness of some saponins declined the consumer's sensory acceptance. At present, studies on how to reduce the acridity of saponin in Brahmi are rare, requiring review of other medicinal plants to appraise. A Moringa study by Indriasari et al. [8] revealed that blanching Moringa 
leaves at $85{ }^{\circ} \mathrm{C}$ for $7.5 \mathrm{~min}$ decreased saponins quantity of Moringa leaves to the lowest but still preserved most of the nutritional value. When blanching Moringa leaves at $95{ }^{\circ} \mathrm{C}$ for $7.5 \mathrm{~min}$, the saponins increased because $95-100{ }^{\circ} \mathrm{C}$ of the temperature softened vegetable tissues, leading to diffusion of water and the compound across a membrane, and increasing the number of saponins. However, Shi et al. [9] found white kidney beans soaking in water (1:7) for $6 \mathrm{~h}$ reduced the amount of saponin B to $3.1 \%$ when increasing the white kidney bean soaking time to $12 \mathrm{~h}$, the quantity of saponin B decreased to 10.1 $\%$. Therefore, factors affecting the depletion of saponin quantity are temperature, boiling time, and soaking time. However, diminishing bitterness of saponin in Brahmi can use salt because Yadav and Singh [10] and Din et al. [11] found that soaking in sodium chloride solution alleviates the astringent of vegetables and fruits. Commonly, sodium chloride is debittering bitter gourd. Thus, it is possible to use salt to reduce the bitterness of Brahmi.

As previously mentioned, saponins in Brahmi benefits the brain by restoring memory and preventing dementia, but they generate a bitter taste. Processing Brahmi before cooking might change the number of saponins and their flavor. Thus, this study aimed to investigate the number of saponins in Brahmi after prepared in different methods before cooking to reduce bitterness and examining consumers' sensory acceptance for food mixed with Brahmi prepared in various techniques. To identify a process of how to prepare Brahmi before cooking for optimal benefits of the body, dementia prevention, and a source of additional fibers. Besides, those who want to eat Brahmi will have a new solution to prepare the ingredient to be in a meal for Thai people.

\section{Materials and methods}

\section{Materials}

Brahmi was collected in August 2020 from Kanchanaburi provinces, Thailand. Sodium chloride was purchased from Thai Refined Salt Co., Ltd, Thailand. Other ingredients for making Brahmi curry purchased from a local market in Nonthaburi province of Thailand included dried red chili, lemongrass, shallot, garlic, turmeric, roasted fish, coconut milk (Lin Brand), palm sugar, and shrimp paste (Tra Chang Brand).

\section{Chemical}

Ethanol (AR grade) and orthophosphoric acid (HPLC grade) were purchased from Qrec, New Zealand. Methanol (HPLC grade) and Acetonitrile (HPLC grade) were purchased from Labscan Asia, Thailand. Sodium hydroxide was purchased from Carlo Erba, Italy. The saponin reference standards are Bacopaside II, and Bacoside A (a mixture of Bacoside $\mathrm{A}_{3}$, Bacopaside I, Bacopasaponin $\mathrm{C}$ isomer, and Bacopasaponin C) were purchased from Natural Remedies, India.

\section{Preparation of Brahmi}

The preparation was started by picking aerial parts of Brahmi at $10 \mathrm{~cm}$ from the apex [12], rinsing with tap water, and cutting into small pieces of $1 \mathrm{~cm}$-in length until $2.4 \mathrm{~kg}$. Then, $1.8 \mathrm{~kg}$ of Brahmi has been reduced its bitterness with a rolling pin. After that, $6 \mathrm{~kg}$ of Brahmi was crumpled with either 0,10 , or $20 \%(\mathrm{w} / \mathrm{w})$ salt and kept at $25{ }^{\circ} \mathrm{C}$ for $1 \mathrm{~h}$. After the salting time, Brahmi was rinsed with tap water 3 times. Then, Brahmi was boiled in a volume of drinking water 6 times than the Brahmi weight at $100{ }^{\circ} \mathrm{C}$ for $3 \mathrm{~min}$ [13]. Finally, Brahmi was dried in a hot air oven (ANC 677 model, China) at $50^{\circ} \mathrm{C}$ for $12 \mathrm{~h}$ and ground with a blender (OTTO BE-127A model, China) to powder for saponin extraction.

\section{Saponin extraction}

After preparation, 4 types of Brahmi as chopped fresh and crumpled with 0,10 , or $20 \%(\mathrm{w} / \mathrm{w})$ salt were extracted using a modified method of Phrompittayarat et al. [14]. The 4 types of Brahmi powder $1 \mathrm{~g}$ were soaked in $10 \mathrm{~mL}$ of distilled water at $25^{\circ} \mathrm{C}$ for $24 \mathrm{~h}$ and squeezed to discard distilled water by hand before $4 \mathrm{~h}$ percolation with $7 \mathrm{~mL}$ of $95 \%$ ethanol per $1 \mathrm{~g}$ of Brahmi powder for 3 times. The pooled ethanolic extract was filtered by filter paper no.1 and dried by rotary evaporator (EYELA N-1000 model, Japan) at $55^{\circ} \mathrm{C}$. Finally, the crude extract was weighed and calculated using Eq. (1).

\%yield $=\frac{\text { weight of powder }}{\text { weight of crude extract }} \times 100$ 


\section{Analysis of saponin content and quantity in Brahmi extract}

The stock standard solution of concentration $2,500 \mu \mathrm{g} / \mathrm{mL}$ was prepared by dissolving $2.5 \mathrm{mg}$ reference standard in $1 \mathrm{~mL}$ HPLC-grade methanol and using HPLC-grade methanol to adjust the standard volume to $2 \mathrm{~mL}$. Then, the stock solution was diluted to $40,100,250$, and $400 \mu \mathrm{g} / \mathrm{mL}$ as working standard solutions for creating the standard graph.

The sample solutions were prepared by re-dissolving $2 \mathrm{~g}$ of crude extract in methanol $1 \mathrm{~mL}$ and filtered through a $0.45 \mu \mathrm{m}$ nylon filter. After that, injection into the chromatographic system (Waters Alliance e2695, USA), separated on an HPLC column (Reliant $\mathrm{C} 18,5 \mu \mathrm{m}, 4.6 \times 150 \mathrm{~mm}^{2}$ ) using an isocratic elution of $0.2 \%$ phosphoric acid: acetonitrile $(65: 35)$, flow rate $0.5 \mathrm{~mL} / \mathrm{min}$, modified from Phrompittayarat et al. [14].

\section{Process of making Brahmi curry}

Brahmi curry was modified from Khi Lek curry recipe. Brahmi crumpled with 0, 10, and $20 \%$ (w/w) salt was used to substitute $100 \%$ Khi Lek in the Khi Lek curry recipe. The curry was prepared as the following:

1. Prepared the curry paste: blended $12.5 \mathrm{~g}$ dried red chili, $30 \mathrm{~g}$ lemongrass, $37.5 \mathrm{~g}$ shallot, $1.25 \mathrm{~g}$ garlic, $5 \mathrm{~g}$ turmeric, $6.25 \mathrm{~g}$ sodium chloride, and $7.5 \mathrm{~g}$ shrimp paste with a blender until fine.

2. Pour $222.5 \mathrm{~g}$ coconut cream into the pot and added curry paste from 1 , and heated until it boiled

3. Added $222.5 \mathrm{~g}$ coconut milk mixed with $222.5 \mathrm{~g}$ of water.

4. Then added $250 \mathrm{~g}$ Brahmi that was crumpled with salt and $375 \mathrm{~g}$ roasted fish.

5. Finally, flavored with $10 \mathrm{~g}$ palm sugar and heated until boiling.

\section{Sensory evaluation}

This study used a 9-point hedonic scale (1 is the lowest level of satisfaction and 9 is the highest level of satisfaction) to evaluate the attributes of sensations. Fifty consumers testing all 3 types of Brahmi curry as concern appearance, color, odor, taste, texture, and overall liking.

\section{Consumer acceptability test}

50 Consumers age between 25 - 45 years old were divided into 2 groups by sex. 23 Males and 27 females were tested and interviewed at Recreation Center, Nonthaburi province, Thailand. The subjects evaluated the $15 \mathrm{~g}$ Brahmi curry with $15 \mathrm{~g}$ of streamed rice. The protocol was approved by Kasetsart University Research Ethics Committee (No. KUREC-SS63/180). All participants were given written informed consent to the study.

\section{Statistical analyses}

The saponin quantity was analyzed by a completely randomized design. The sensory evaluation acceptance testing was analyzed by a randomized complete block design. Analysis of variance (ANOVA) was conducted to determine whether there was any statistically significant difference using Duncan's New Multiple Range Test (DNMRT) with a confidence interval of $95 \%$. The Statistical analysis was performed by using $\mathrm{R}$ program version 3.4.1 (R Core Team 2017).

\section{Results and discussion}

\section{Study on the yield of Brahmi extract powder}

The percent yield of 4 different Brahmi preparation methods (Figure 1) was not significantly different $(p \geq 0.05)$ because the factors that affected the percent yield were solvent and the extraction method [15]. In this study, $95 \%$ ethanol was used because this solvent was the most common extraction for saponins [16], using a similar extraction method. Therefore, the percentage of Brahmi extract yield of different Brahmi treatments was similar to the previous one [15].

\section{Analysis of saponin quantity in Brahmi extract}

The results of saponin quantity in 4 different Brahmi preparation methods (Table 1) showed that the various preparation methods influenced the remaining saponin quantity. Fresh Brahmi had the highest saponin quantity $(3.40 \pm 0.00 \mathrm{~g} / \mathrm{kg})$, boiled Brahmi after crumpled with $0 \%$ salt had the lowest saponin quantity $(2.00 \pm 0.11 \mathrm{~g} / \mathrm{kg})$, and the boiled Brahmi after crumpled with 10 and $20 \%$ salt had $2.69 \pm 0.02$ and $2.61 \pm 0.11 \mathrm{~g} / \mathrm{kg}$, respectively. The boiling Brahmi in water at $100{ }^{\circ} \mathrm{C}$ significantly declined the total saponin quantity $(p<0.05)$. This result corresponded to the previous study of Phrompittayarat et al. [17] who found that the number of Bacoside $\mathrm{A}_{3}$ and Bacopaside I were drastically diminished when Brahmi 
extract was stored at $80{ }^{\circ} \mathrm{C}$ compared to below $60{ }^{\circ} \mathrm{C}$ also corresponds to the previous study of Liu et al. [18] which found that the saponins in Bitter gourd such as 3 $\beta, 7 \beta, 25$-trihydroxycucurbita-5,23(E)-dien19-al and momordicoside L were extremely sensitive to heat treatment, particularly when they were heated at $100{ }^{\circ} \mathrm{C}$ for more than $10 \mathrm{~min}$ and under $121{ }^{\circ} \mathrm{C}$ for $20 \mathrm{~min}$ which might modify the bioactive components or bitter flavor of the bitter gourd extracts.

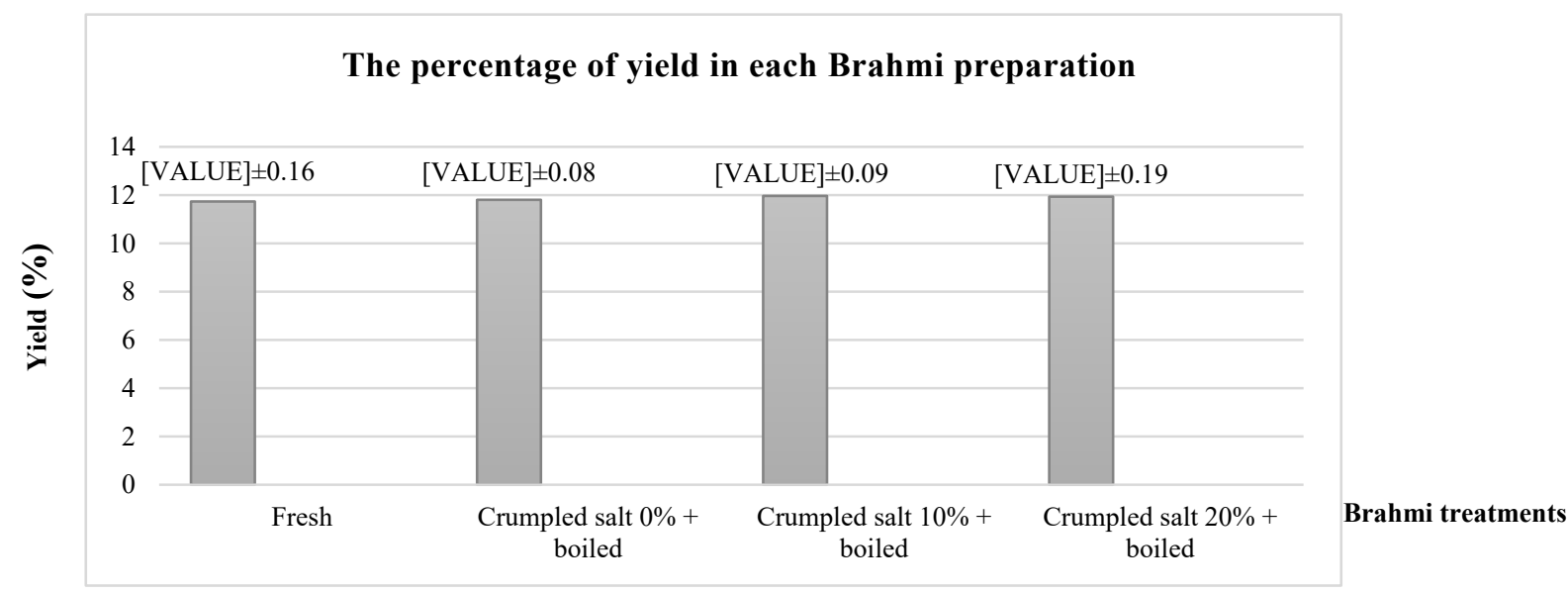

Figure 1 The percentage of yield of Brahmi extract prepared with different pre-treatments.

Table 1 The amount of saponin in Brahmi extract prepared by different methods $(n=3)$.

\begin{tabular}{|c|c|c|c|c|c|c|}
\hline \multirow[b]{2}{*}{ Preparation } & \multicolumn{5}{|c|}{ Amount of saponins as mean $\pm \mathrm{SD}(\mathrm{g} / \mathrm{kg})$} & \multirow[b]{2}{*}{ Total } \\
\hline & Bacoside $\mathbf{A}_{3}$ & Bacopaside Il & $\begin{array}{c}\text { Bacopasaponin } \mathbf{C} \\
\text { isomer }\end{array}$ & Bacopasaponin $\mathrm{C}$ & Bacopaside I & \\
\hline Fresh & $0.67 \pm 0.0^{\mathrm{a}}$ & $0.73 \pm 0.00^{\mathrm{a}}$ & $0.57 \pm 0.01^{\mathrm{a}}$ & $0.75 \pm 0.02^{\mathrm{a}}$ & $0.69 \pm 0.00^{\mathrm{a}}$ & $3.40 \pm 0.00^{\mathrm{a}}$ \\
\hline $\begin{array}{l}\text { Crumpled salt } \\
0 \%+\text { boiled }\end{array}$ & $0.11 \pm 0.01^{\mathrm{d}}$ & $0.47 \pm 0.03^{\mathrm{c}}$ & $0.42 \pm 0.02^{\mathrm{c}}$ & $0.54 \pm 0.04^{b}$ & $0.46 \pm 0.07^{\mathrm{b}}$ & $2.00 \pm 0.11^{\mathrm{c}}$ \\
\hline $\begin{array}{l}\text { Crumpled salt } \\
10 \%+\text { boiled }\end{array}$ & $0.26 \pm 0.00^{\mathrm{b}}$ & $0.69 \pm 0.00^{\mathrm{ab}}$ & $0.52 \pm 0.00^{\mathrm{b}}$ & $0.60 \pm 0.00^{\mathrm{b}}$ & $0.63 \pm 0.02^{\mathrm{a}}$ & $2.69 \pm 0.02^{b}$ \\
\hline $\begin{array}{l}\text { Crumpled salt } \\
20 \%+\text { boiled }\end{array}$ & $0.23 \pm 0.00^{\mathrm{c}}$ & $0.65 \pm 0.00^{\mathrm{b}}$ & $0.50 \pm 0.02^{\mathrm{b}}$ & $0.57 \pm 0.04^{\mathrm{b}}$ & $0.66 \pm 0.05^{\mathrm{a}}$ & $2.61 \pm 0.11^{\mathrm{b}}$ \\
\hline
\end{tabular}

Legand: ${ }^{1}$ All data were represented as mean \pm SD. ${ }^{2}$ Different letters in same column indicate significant difference at $p<0.05$ using 1-way ANOVA followed by Duncan multiple range test. ${ }^{3}(\mathrm{~g} / \mathrm{kg})$ means the amount of saponin $(\mathrm{g})$ per fresh weight $(\mathrm{kg})$.

Considering all 5 saponins, the quantity of Bacoside $\mathrm{A}_{3}$, Bacopasaponin $\mathrm{C}$ isomer, and Bacopasaponin $\mathrm{C}$ of boiled Brahmi crumpling with 0,10 , and $20 \%$ salt were significantly lower than fresh Brahmi $(p<0.05)$. However, the Bacopaside I quantity of boiled Brahmi crumpling with 10 and 20 $\%$ salt was not significantly lower than fresh Brahmi $(p \geq 0.05)$, while the Bacopaside I of boiled Brahmi crumpling with $0 \%$ salt was significantly lower than fresh Brahmi $(p<0.05)$. The results showed that the Bacopaside I stabilize after crumped with salt compared with fresh Brahmi (Table 1).

Moreover, the quantity of Bacoside $\mathrm{A}_{3}$, Bacopaside II, Bacopasaponin $\mathrm{C}$ isomer, and Bacopaside I of boiled Brahmi crumpling with $0 \%$ salt were significantly lower than boiled Brahmi crumpling with 10 and $20 \%$ salt $(p<0.05)$. Therefore, salt stabilized the saponin quantity in crumpled Brahmi. The saponin structure comprises 2 parts, the sugar molecule and non-sugar molecule called "aglycone" [19]. The saponin glycoside is water-soluble. The crumpling of Brahmi with salt before boiling caused the salt to diffuse into the cells of Brahmi leaves [20]. When boiling, the saponin quantity in boiled Brahmi crumpling with 10 and $20 \%$ salt was released less than the saponin quantity in Brahmi that not crumpled with salt (crumpling with $0 \%$ salt). The saponin quantity in Brahmi that not crumpled with salt (crumpled 
with $0 \%$ salt) before boiling was significantly lower than the saponin quantity in the boiled Brahmi that crumpling with 10 and $20 \%$ with salt (Table 1).

\section{Sensory attributes of Brahmi curry}

The sensory evaluation of Brahmi curry prepared by boiled Brahmi crumpled with 0,10 , and $20 \%$ salt (Table 2) found that the appearance, color, and odor of Brahmi curry were not significantly different between the Brahmi curry with different salt concentration crumpled preparation of Brahmi $(p \geq 0.05)$. Taste texture and overall liking were significantly different between the Brahmi curry with different salt concentration crumpled preparation of Brahmi $(p<0.05)$. Brahmi curry prepared by boiled Brahmi crumpled with $10 \%$ salt had the highest sensory scores for taste, texture, and overall liking at the level of "like slightly to like moderately" with values of $6.78 \pm 1.91,6.96 \pm 1.69$ and $6.96 \pm 1.64$, respectively. This study resulted was not following the previous sensory evaluation of the Khi Lek curry in 30 panelists, which showed that it was no significant difference between treatments that were diminished the bitterness because a high concentration of coconut milk and spices in curry that might have concealed its taste, especially the bitterness [13]. However, the methods for minimizing the bitterness of Brahmi had different procedures. Khi Lek was not mashing by rolling pin and crumpling with salt. Besides that, the bioactive compound causing bitterness in Brahmi are saponins, while the bioactive compound causing bitterness in Khi Lek are alkaloids. Therefore, the taste, texture, and overall liking of Brahmi curry were significantly different.

For the overall liking scores, this study found that Brahmi curry prepared by boiled Brahmi crumpled with $10 \%$ salt was not significantly different from Brahmi curry prepared by boiled Brahmi crumpled with $0 \%$ salt $(p \geq 0.05)$. However, it was significantly different with Brahmi curry prepared by boiled Brahmi crumpled with $20 \%$ salt $(p<0.05)$. It was probably because of the texture scores. The texture scores of Brahmi curry prepared by boiled Brahmi crumpled with $10 \%$ salt were not significantly different from the texture scores of Brahmi curry prepared by Brahmi crumpled with $0 \%$ salt $(p \geq 0.05)$. Nevertheless, the texture scores of Brahmi curry prepared by Brahmi crumpled with $20 \%$ salt were significantly different. It was shown that increasing the amount of salt used for crumpling affected the texture of Brahmi curry because the salt had a slight hardening effect on the cellulose of vegetables that helped extract the juices [21]. Therefore, the texture of Brahmi that crumpled with salt remodeled when the amount of salt increasing.

The tasting scores showed consumer's sensory acceptance of the bitterness of food mixed with Brahmi prepared in various techniques. Brahmi curry prepared by boiled Brahmi crumpled with $10 \%$ salt had the highest scores and was significantly different from Brahmi curry prepared by boiled Brahmi crumpled with 0 and $20 \%$ salt $(p<0.05)$. It was probably because of the amount of salt. Crumpling with $0 \%$ salt was not only reduced the bitterness but also drastically decreased saponin quantity compared to fresh Brahmi (Table 1). When Brahmi was crumpled with salt and kept at $25^{\circ} \mathrm{C}$ for $1 \mathrm{~h}$, the salt moved from the high concentration region to the low concentration region of Brahmi [22]. Thus, the bitterness of Brahmi could be masked with the salty taste [23].

Table 2 Sensory scores of Brahmi curry prepared using boiled Brahmi crumpled with different salt concentrations.

\begin{tabular}{lccc}
\hline \multirow{2}{*}{ Attribute } & \multicolumn{3}{c}{ Preparation } \\
\cline { 2 - 4 } & Crumpled salt 0\% + boiled & Crumpled salt 10 \% + boiled & Crumpled salt 20 \% + boiled \\
\hline Appearance $^{\mathrm{ns}}$ & $6.24 \pm 1.73$ & $6.54 \pm 1.71$ & $5.92 \pm 1.74$ \\
Color $^{\mathrm{ns}}$ & $6.58 \pm 1.46$ & $6.74 \pm 1.54$ & $6.44 \pm 1.58$ \\
Odor $^{\mathrm{ns}}$ & $6.54 \pm 1.68$ & $6.58 \pm 1.55$ & $6.34 \pm 1.41$ \\
Taste $^{\text {Texture }}$ & $5.84 \pm 2.28^{\mathrm{b}}$ & $6.78 \pm 1.91^{\mathrm{a}}$ & $5.22 \pm 2.37^{\mathrm{b}}$ \\
Overall liking & $6.34 \pm 1.83^{\mathrm{ab}}$ & $6.96 \pm 1.69^{\mathrm{a}}$ & $6.00 \pm 1.86^{\mathrm{b}}$ \\
\hline
\end{tabular}

Legand: ${ }^{1}$ All data were represented as mean \pm SD of 50 panelists. ${ }^{2}$ Different letters in same row indicate significant difference at $p<0.05$ using 1 -way ANOVA followed by Duncan multiple range test. ${ }^{3} 9$-points hedonic scale $(1=$ Dislike extremely, $5=$ Neither Like nor Dislike, $9=$ Like Extremely. 
Moreover, it was noteworthy that the bitterness of Brahmi might not be caused by 5 saponins which enhancing memory and preventing dementia. Figure 3 showed the chromatograms of 5 saponins in Brahmi extract obtained from different preparation methods. These results displayed that the saponin quantity of boiled Brahmi crumpled with $0 \%$ salt was lower than the saponin quantity of boiled Brahmi crumpled with $10 \%$ salt. On the other hand, the tasting scores of Brahmi curry with boiled Brahmi crumpled with $10 \%$ salt was higher than Brahmi curry with boiled Brahmi crumpled with $0 \%$ salt (Table 2). This finding showed that higher remaining saponin quantity did not result in a lower tasting score. Thus, the bitterness of Brahmi might be caused by the other saponins in Brahmi because a single plant species might contain a complex mixture of saponins. For example, the characterized soybean saponins include 3 groups of compounds: soyasaponins A, B, and E categorized according to the soyasapogenol in their structure [24]. Soyasaponins A is the only saponin in soy that has bitterness. There are 12 types of saponin under the Bacopasaponins group in Brahmi [25]. So, it was possible about the bitterness of Brahmi was not caused by 5 saponins that prevent dementia but caused by the other.

However, the tasting scores of Brahmi curry with boiled Brahmi crumpled with $20 \%$ salt were not significantly different from Brahmi curry with boiled Brahmi crumpled with $0 \%$ salt $(p \geq 0.05)$. It was probably because of excessive salt for crumpling that affected on texture and tasting of Brahmi curry with boiled Brahmi crumpled with $20 \%$ salt.

The appropriate Brahmi preparation for cooking was selected based on sensory attributes of Brahmi curry (Table 2) and saponin quantity (Table 1). Boiled Brahmi that crumpled with $10 \%$ salt had the highest for both sensory score and saponin quantity. Also, some of the saponins were not significantly different from fresh Brahmi $(p \geq 0.05)$. Thus, boiled Brahmi that crumpled with $10 \%$ salt is recommended for cooking, and it needs to be consumed for $40 \mathrm{~g}$ of boiled Brahmi that crumpled with 10 $\%$ salt to be equivalent to a consumption of $30 \mathrm{~g}$ fresh Brahmi because 1 tablet of Brahmi supplement extract equivalent to $30 \mathrm{~g}$ of fresh Brahmi [26], and boiled Brahmi that crumpled with $10 \%$ salt has a lower saponin quantity than fresh Brahmi.

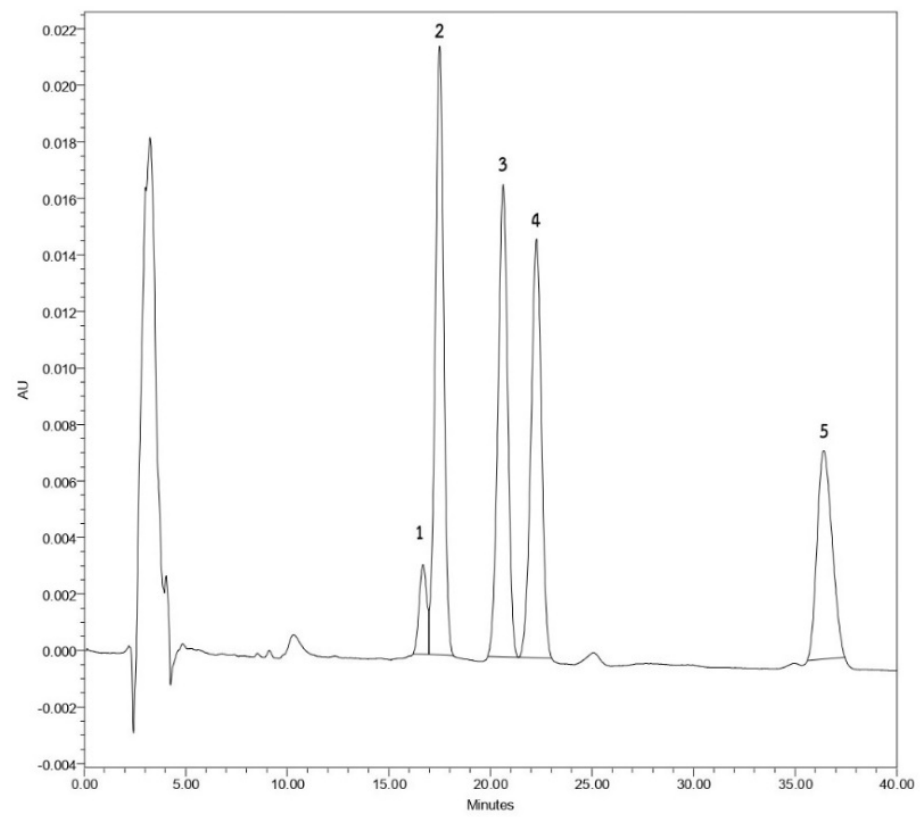

Figure 2 HPLC-chromatograms of the mixture of 5 reference standards $(40 \mu \mathrm{g} / \mathrm{mL})$. The peaks are identified as follows: (1) Bacoside $\mathrm{A}_{3}$; (2) Bacopaside II; (3) Bacopasaponin C isomer; (4) Bacopasaponin C and (5) Bacopaside I. 

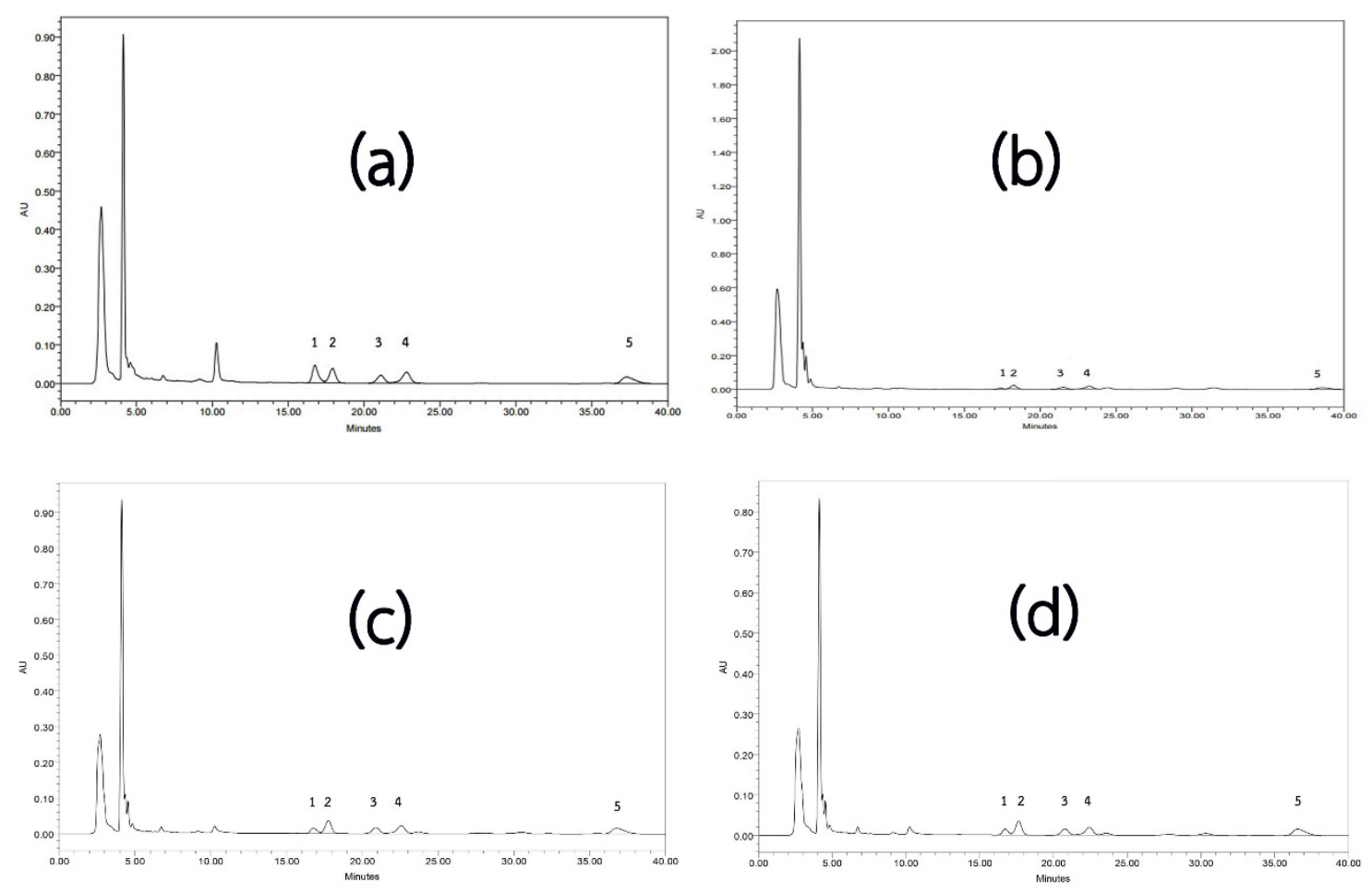

Figure 3 HPLC chromatogram of Brahmi extract obtained from (a) Fresh; (b) Crumpled salt $0 \%+$ boiled; (c) Crumpled salt $10 \%+$ boiled; (d) Crumpled salt $20 \%+$ boiled. The peaks are identified as follows: (1) Bacoside $\mathrm{A}_{3}$; (2) Bacopaside II; (3) Bacopasaponin C isomer; (4) Bacopasaponin C and (5) Bacopaside I.

\section{Conclusions}

The boiled Brahmi crumpled with $10 \%$ salt $(\mathrm{w} / \mathrm{w})$ before cooking had the highest remaining saponin and was the most acceptable from consumers. Thus, the suitable preparation of Brahmi before cooking for reducing bitterness and maintaining high saponin quantity are crumpling with $10 \%$ salt $(\mathrm{w} / \mathrm{w})$ before boiling in water at $100{ }^{\circ} \mathrm{C}$ for $3 \mathrm{~min}$, which can be a new alternative of consuming Brahmi in food for preventing dementia.

\section{Acknowledgements}

We would like to thank Miss Sookruthai Wongsubin, a staff of Central Instrument Facility, Faculty of Science, Mahidol University, Thailand, for generously providing the facilities, and all people in this department for teaching, helping, and giving advice on the laboratory session.

\section{References}

[1] C Sardsaengjun. Bacopa: Herb for brain health. Thammasat Med. J. 2013; 13, 554-60.

[2] XT Le, HTN Pham, TV Nguyen, KM Nguyen, K Tanaka, H Fujiwara and K Matsumoto. Protective effects of Bacopa monnieri on ischemia-induced cognitive deficits in mice: The possible contribution of bacopaside I and underlying mechanism. J. Ethnopharmacol. 2015; 164, 37-45.

[3] K Pravina, K Ravindra, KS Goudar, DR Vinod, AJ Joshua, P Wasim, K Venkateshwarlu, VS Saxena and A Amit. Safety evaluation of BacoMind in healthy volunteers: A phase I study. Phytomedicine 2007; 14, 301-8.

[4] N Rungrojvuthikul. 2014, The effect of Bacopa monnieri Wettst extract to memory performance study. Ph. D. Dissertation. Mae Fah Luang University, Thailand.

[5] A Kumar, A Singh and Ekavali. A review on Alzheimer's disease pathophysiology and its management: An update. Pharmacol. Rep. 2015; 67, 195-203. 
[6] GP Savage. Saponins. In: B Caballero, LC Trugo and PM Finglass (Eds.). Encyclopaedia of food sciences and nutrition. Academic Press, United States, 2003, p. 5095-8.

[7] KR Price, NM Griffiths, CL Curl and GR Fenwick. Undesirable sensory properties of the dried pea (Pisum sativum). The role of saponins. Food Chem. 1985; 17, 105-15.

[8] Y Indriasari, Wignyanto and S Kumalaningsih. Effect of blanching on saponins and nutritional content of moringa leaves extract. J. Food Res. 2016; 5, 55-60.

[9] J Shi, SJ Xue, Y Ma, D Li, Y Kakuda and Y Lan. Kinetic study of saponins B stability in navy beans under different processing conditions. J. Food Eng. 2009; 93, 59-65.

[10] AK Yadav and SV Singh. Osmotic dehydration of fruits and vegetables: A review. J. Food Sci. Technol. 2014; 51, 1654-73.

[11] A Din, SAH BUkhari, A Salam and B Ishfaq. Development of functional and dietetic beverage from bitter gourd. Internet J. Food Saf. 2011; 13, 355-60.

[12] W Phrompittayarat, K Jetiyanon, S Wittaya-Areekul, W Putalun, H Tanaka, I Khan and K Ingkaninan. Influence of seasons, different plant parts, and plant growth stages on saponin quantity and distribution in Bacopa monnieri. Songklanakarin J. Sci. Technol. 2011; 33, 193-9.

[13] C Teangpook, U Paosangtong, Y Titatarn, S Onhem and W Puminat. Production and nutrition of Khi Lek (Siamese cassia) curry from central Thailand. Kasetsart J. Nat. Sci. 2011; 45, 510-20.

[14] W Phrompittayarat, S Wittaya-areekul, K Jetiyanon, W Putalun, H Tanaka and K Ingkaninan. Determination of saponin glycosides in Bacopa monnieri by reversed phase high performance liquid chromatography. Thai Pharm. Health Sci. J. 2007; 2, 26-32.

[15] W Phrompittayarat, W Putalun, H Tanaka, K Jetiyanon, S Wittaya-areekul and K Ingkaninan. Comparison of various extraction methods of Bacopa monnieri. Naresuan Univ. J. Sci. Technol. 2013; 15, 29-34.

[16] K Hostettmann and A Marston. Saponins. Cambridge University Press, New York, 2005, p. 122-74.

[17] W Phrompittayarat, S Wittaya-Areekul, K Jetiyanon, W Putalun, H Tanaka and K Ingkaninan. Stability studies of saponins in Bacopa monnieri dried ethanolic extracts. Planta Med. 2008; 74, 1756-63.

[18] YJ Liu, YJ Lai, R Wang, YC Lo and CH Chiu. The Effect of thermal processing on the saponin profiles of Momordica charantia L. J. Food Qual.2020, 2020, 8862020.

[19] MMAE Aziz, AS Ashour and ASG Melad. A review on saponins from medicinal plants: Chemistry, isolation, and determination. J. Nanomed. Res. 2019; 8, 282-8.

[20] NCERT. Biology textbook for class XI. National Council of Educational Research and Training. New Delhi, India, 2019, p. 176-7.

[21] FR Lanman and ES Minton. The effect of the use of salt in cooking vegetables. Ohio Agricultural Experiment Station, Wooster, Ohio, 1927, p. 3-5.

[22] RS Rashima, M Maizura and U Uthumporn. Effects of debittering treatments on the physical properties and antioxidant capacity of bitter gourd extracts. Adv. J. Food Sci. Technol. 2017; 13, 253-61.

[23] RSJ Keast, PAS Breslin and GK Beauchamp. Suppression of bitterness using sodium salts. Chimia $2001 ; \mathbf{5 5}, 441-7$.

[24] O Guclu-Ustundagand and G Mazza. Saponins: Properties, applications and processing. Crit. Rev. Food Sci. Nutr. 2007; 47, 231-58.

[25] PBS Murthy, VR Raju, T Ramakrisana, MS Chakravarthy, KV Kumar, S Kannababu and GV Subbaraju. Estimation of twelve bacopa saponins in Bacopa monnieri extracts and formulations by high-performance liquid chromatography. Chem. Pharm. Bull. 2006; 54, 907-11.

[26] K Ingkaninan. Brahmi: Herb maintain memory. Naresuan University, Phitsanulok, Thailand, 2018, p. 253-4. 